\title{
LITERATURA COMPARADA ONTEM E HOJE: CAMPO EPISTEMOLÓGICO DE ANSIEDADES E INCERTEZAS
}

\author{
Anselmo Peres Alós*
}

\begin{abstract}
: this paper aims at discussing some critical points when it comes to the development of the comparative literature from its origins until the contemporary anxieties of the discipline. It is also discussed here some of the non-eurocentric theoretical contributions, which are extremely relevant to the discipline in these times hauted by the epistemic incertitudes of the $21^{\text {st }}$ century.
\end{abstract}

KEYWORDS: comparative literature, canon, history, theory

\section{DAS ORIGENS DE UM CAMPO EPISTEMOLÓGICO}

Um vislumbre pela história da constituição do comparatismo como campo de investigação nos estudos literários evidencia suas conexões, desde suas origens até as suas tendências contemporâneas, de seus estreitos vínculos com as políticas da produção cultural. Ao longo das últimas décadas, a literatura comparada ramificou-se, ampliando seu campo de forma a dar conta das relações entre culturas distintas, bem como dos diferentes extratos culturais de uma mesma comunidade discursiva identificada sob a égide da categoria nação. Nos seus mais recentes desdobramentos, os estudos comparatistas começam a questionar as definições hegemônicas e historicamente consagradas sobre os limites do campo literário, sobre a legitimidade dos discursos teóricos que tomam a literatura como objeto, e sobre o papel do ensino de literatura nas universidades (SCHMIDT, 2005, p. 113-130).

Desde as primeiras décadas do século XIX, intelectuais do porte de Mme. de Staël preocuparam-se com a necessidade de se conhecer as literaturas e as culturas estrangeiras a partir de um viés que tomasse a comparação como princípio epistemológico. Se a noção de Weltliteratur, formulada por Goethe, pode ser questionada hoje pelas suas tendências eurocêntricas, nos princípios do século XIX (no apogeu das crenças positivistas) ela se mostrava como um primeiro passo em direção à compreensão da diversidade cultural, a partir de estudos sobre as questões de fontes, influências e pontos de contato entre diferentes literaturas nacionais ${ }^{1}$. O surgimento do

\footnotetext{
* Professor da Universidade Federal de Santa Maria (UFSM).

${ }^{1}$ No início do século XXI, dois textos assinados por Franco Moretti, intitulados "Conjectures on World Literature" (2000) e "More Conjectures on World Literature" (2003), publicados na conceituada revista
} 
termo "literatura comparada", referindo-se a um campo de atuação específico nos estudos literários, deu-se no momento da consolidação dos Estados Nacionais na Europa, e seus pressupostos estavam atrelados, ainda que de maneira incipiente, às discussões sobre as questões de fronteira, cultura e identidade nacional. Cabe destacar, pois, que desde os seus primórdios, a literatura comparada mostra-se preocupada com o diálogo cultural de calibre internacional.

Uma das discussões a permear o comparatismo desde seu nascimento até a contemporaneidade é a que diz respeito à sua definição como campo disciplinar, ao seu objeto de investigação e aos seus métodos e pressupostos (COUTINHO, 2001, p. 7-12). Talvez por isso, alguns dos estudos e ensaios clássicos sobre o que hoje pode ser chamado de uma epistemologia comparatista deixem entrever, em seus títulos, uma vaga sombra de incertezas. Basta lembrar aqui de estudos como "O que é a literatura comparada?", de Benedetto Crocce (1948, p. 71-76), do livro homônimo de Pichois e Rousseau (1971), ou ainda, do famoso artigo intitulado "Crisis in the Comparative Literature", de René Wellek (1994, p. 108-119)².

De acordo com Henry H. H. Remak (1980, p. 429-437), a literatura comparada pode ser compreendida como o estudo da literatura para além das fronteiras de um país particular, e o estudo das relações entre literatura, de um lado, e de outras áreas do conhecimento (as artes, a filosofia, a sociologia), de outro. O comparatismo configurase como o estudo das diversas literaturas nas suas relações entre si, isto é, na medida em que umas estão ligadas às outras na inspiração, no conteúdo, na forma e no estilo. A esta definição, que remonta a Paul Van Tieghem (1951), Remak acrescenta a aproximação de cunho interdisciplinar, posto que sugere ser importante para o comparatismo o confronto entre literatura e outros domínios do conhecimento.

O pronunciamento de René Wellek, realizado nos anos 50 durante o II Encontro da Associação Internacional de Literatura Comparada (AILC), instaurou uma ruptura com a chamada "escola francesa", inaugurando o que passou a ser chamado de "escola americana" no comparatismo. A "escola francesa" definia-se por seus vínculos a concepções positivistas e lineares de história, recaindo em julgamentos de valor que valorizavam as fontes em detrimento das influências. Seus métodos eram rigorosamente historicistas, buscando linhas de evolução pautadas nos estudos de fontes e influências, com vistas à elaboração de uma "história da literatura geral". Para os estudiosos alocados sob tal rubrica, era indispensável ao comparatismo que as obras em cotejo fossem provenientes de culturas nacionais distintas, e que tais investigações abarcassem obras escritas em línguas distintas. Wellek propõe o entrelaçamento e o diálogo constante entre a história, a crítica e a teoria da literatura. Ao definir o comparatismo por sua perspectiva metodológica, Wellek abre caminho para o estabelecimento de um diálogo com a teoria da literatura, que vinha então sendo formulada pelo formalismo russo, pelo estruturalismo tcheco e pela estilística de inspiração germanófila.

A chamada "escola americana" de literatura comparada foi marcada pelos

New Left Review, reacenderam as discussões em torno da definição, do alcance e da validade da noção de Weltliteratur. A discussão tomou fôlego e foi estendida por Pascale Casanova em seu livro The World Republic of Letters (2004) e no artigo "Literature as a World" (2005), também publicado na New Left Review. Aijaz Ahmad, em "Show me the Zulu Proust: Some Thoughts on World Literature" (publicado pela Revista Brasileira de Literatura Comparada, em 2010) demonstra o quanto a noção supostamente cosmopolita e abrangente de Weltliteratur é, em verdade, tributária de um olhar imperialista e etnocêntrico sobre as manifestações do fenômeno literário em escala global.

${ }^{2}$ A tradução deste trabalho foi incluída no volume Literatura comparada: textos fundadores, organizada por Tânia Franco Carvalhal e Eduardo Coutinho (1994). 
influxos das teorias literárias de cunho imanentista, como o formalismo, o estruturalismo e o New Criticism estadunidense. Mais aberta a estudos paralelísticos, a "escola americana" admitia o estudo de obras e autores dentro de uma mesma literatura nacional. Como decorrência dos influxos imanentistas, acreditava-se que o valor artístico de uma obra era intrínseco aos elementos textuais. Em outras palavras, o critério de valor era pautado na literariedade, categoria formulada pelos formalistas russos em seus estudos de poética, já no início do século XX. Se por um lado a "escola americana" sinaliza um avanço e uma ampliação dos interesses comparatistas, possibilitando abordagens desvinculadas de preceitos de ordem transcendental e da crítica impressionista, por outro ela desvalorizou um importante aspecto: o do estudo dos vínculos entre a literatura e a cultura, a política e a história das ideias. Nas correntes contemporâneas do comparatismo, contudo, são valorizadas as análises que privilegiam simultaneamente tanto os aspectos formais quanto a interação do texto literário com outros elementos da "série social" - expressão usada por Iuri Tynianov (2001, p. 122139) para descrever o conjunto de elementos extrínsecos e paralelos ao objeto literário de maneira a recontextualizar a literatura em relação ao histórico e ao social, permitindo a recuperação de importantes questões de fundo, tais como as que dizem respeito à função social da literatura.

René Etiemble, em Comparaison n'est pas raison (1963), foi um dos primeiros comparatistas que se preocupou com questões relacionadas ao colonialismo que uma literatura ou cultura exercia sobre outra(s). Etiemble defendia a necessidade de que os estudos comparatistas dedicassem atenção às literaturas ditas marginais no debate comparatista, tais como as latino-americanas e as africanas, partindo do pressuposto de que o projeto de uma Weltliteratur ou de uma literatura geral jamais poderia ter a pretensão de representatividade se incluísse apenas as literaturas europeias e norteamericanas. Pode-se afirmar, pois, que Etiemble foi uma voz pioneira na denúncia do eurocentrismo metropolitano nos interstícios do comparatismo. Deve-se ainda a Etiemble a admissão da legitimidade, dentro do comparatismo, de estudos que buscavam fontes e influências mesmo onde inexistiam evidências factuais de contato, reconhecendo assim a validade de se estabelecer paralelismos de pensamento. Surge então a primeira fissura no campo hegemônico dos estudos de "fontes e influências" no contexto francês, a partir do qual se dará o desenvolvimento de estudos de mitocrítica (dedicados ao rastreamento de mitos e arquétipos em diferentes literaturas ao longo do tempo) e de imagologia (centrados na investigação das imagens e projeções que uma determinada literatura nacional realiza com relação à literatura de outra nação). Contudo, a proposta de Etiemble propõe a construção de um modelo comparatista que busca valores invariantes em diferentes culturas. Com a valorização de tais "constantes", de cunho universalista, apaga-se a possibilidade de contemplar as diferenças entre as literaturas nacionais e os aspectos históricos relativos a tradições literárias particulares, o que minimiza a produtividade desse pós-colonialismo avant la lettre dos postulados de Etiemble.

A partir do final dos anos 60, o pensamento comparatista do Leste Europeu passa a ganhar espaço nos congresso internacionais da Associação Internacional de Literatura Comparada. Um dos nomes de destaque foi o de Victor Zhirmunsky. Realizando seus estudos no contexto soviético, ele aproxima pressupostos das teorias do formalismo com o pensamento marxista para elaborar seu modelo de trabalho. Segundo ele, coletivos humanos em semelhantes condições históricas produzem manifestações literárias aparentadas, mesmo quando não há contato ou fluxo de influências entre estes 
diferentes agrupamentos culturais (ZHIRMUNSKY, 1994, p. 199-214). Como exemplo, ele aponta a similitude da poesia produzida no período feudal da Europa Ocidental e aquela produzida no contexto do feudalismo do Extremo Oriente. Reconhece ainda a importância da comparação entre textos literários, desde que esta não recaia em uma valorização excessiva de aspectos exclusivamente formais e/ou imanentes. Outra importante contribuição, neste mesmo sentido, foi a do romeno Adrian Marino, na década de 80, cujo trabalho volta a fomentar as discussões em torno da "crise da literatura comparada" assinalada por Wellek, ainda nos anos 50 (destaque especial deve ser dado ao seu livro Comparatisme et théorie de la literature, publicado em 1988). Segundo Marino, esta "crise" nunca foi resolvida, pois o comparatismo ainda não havia solucionado de maneira satisfatória a definição do seu objeto de estudo.

Como alternativa para dar conta desse impasse, Marino sugere uma conversão radical do comparatismo para o campo da teoria. Importa assinalar aqui que a noção de "teoria" não deve ser entendida em sentido estrito de "teoria da literatura", mas de maneira ampla, como uma espécie de "novo gênero de escrita acadêmica", tal como assinala Jonathan Culler em On Deconstruction: Theory and Criticism after Structuralism (1982). Instaura-se assim uma busca pelo que Marino chamará de invariantes estruturais do texto literário. Se por um lado as reflexões do comparatista romeno permitem instaurar os prolegômenos de uma poética comparada, por outro "apagam" a importância das diferenças culturais, fator crucial no estudo de tradições literárias subalternizadas pelo discurso comparatista eurocêntrico, tais como aquelas situadas no contexto das literaturas africanas, das latino-americanas e das literaturas do subcontinente indiano.

Minimizar a importância das diferenças culturais em prol da legitimação de uma "literatura universal" desvela, uma vez mais, o risco de se tomar as tradições literárias da Europa Ocidental como paradigma na formulação das "invariantes" literárias valorizadas pela proposta de "poética comparada" de Adrian Marino. Entre as vantagens da proposta sugerida pelo comparatista romeno, encontra-se a solução para o impasse sobre o status científico dos estudos literários, o que é resolvido através da referência à literariedade como medida de valoração do objeto literário. Entre as desvantagens, está o isolamento do discurso literário face aos outros discursos sociais. Em nome da autonomia do método comparatista, na proposta de Adrian Marino, a literatura comparada fecha-se à possibilidade de diálogo com os outros campos de saber, eclipsando, desta forma, a possibilidade das investigações inter- e transdisciplinares no campo das investigações literárias.

\section{DOS REPORT ON PROFESSIONAL STANDARDS AOS DESDOBRAMENTOS DO COMPARATISMO NA AMÉRICA LATINA}

Fundada em 1960, nos Estados Unidos, a American Comparative Literature Association (ACLA) atualmente é reconhecida como a mais importante associação de pesquisadores no campo das abordagens transculturais de literaturas e culturas dos Estados Unidos. Tal como pode ser verificado no website da instituição, a ACLA define-se explicitamente em prol das abordagens transdisciplinares: "comparative literature promotes the study of intercultural relations that cross national boundaries, multicultural relations with a particular society, and interactions between literature and 
other forms of human activity" (www.acla.org/about.html). Este breve trecho, ao ser lido desavisadamente por um comparatista neófito, pode causar a impressão de que a ideia de uma disciplina de amplos horizontes, aberta ao diálogo inter- e transdisciplinar, foi uma constante ao longo da história do desenvolvimento do campo de estudos comparatistas. Para os iniciados, todavia, familiarizados com alguns dos pontos de polêmica que já figuram nos manuais da disciplina, é visível que a atual geografia conceitual que marca os limites da literatura comparada resulta de intensos debates e querelas que remontam ao nascedouro da disciplina, no século XIX, e que se estendem ao longo de toda a sua história: pode-se lembrar, a título de exemplo, as dificuldades de definição dos limites entre a Literatura Geral (definição tributária da noção de Weltliteratur, utilizada pela primeira vez por Goethe em 1927) e a Literatura Comparada, da qual se ocuparam, entre outros, Otto Maria Carpeaux, René Wellek e Warren Austin, ou a divisão da disciplina em "escolas" distintas, em função de suas tendências ora mais historicistas, mesológicas e crenológicas (a "escola francesa"), ora mais imanentistas e formalistas (a "escola americana" e a hegemonia do new criticism e da close reading).

Em 1965, o primeiro relatório (com o sintomático subtítulo "Report on Professional Standards") foi preparado e apresentado à ACLA, por um comitê então dirigido por Harry Levin. Dez anos depois, Tom Greene dirigiu o comitê que redigiu o segundo relatório, apresentado em 1975. Na década seguinte, mais especificamente em 1985, o relatório foi considerado insatisfatório, sendo vetado e desconsiderado. Finalmente, em 1992, em posse dos dois relatórios anteriores, Charles Bernheimer aceitou a tarefa de dirigir o comitê responsável pelo terceiro relatório. Após a redação e submissão do relatório, este terminou por ser objeto de discussão em um dos dois painéis coordenados pela ACLA durante o encontro da Modern Languages Association (MLA), com a participação de Mary-Louise Pratt e Michel Riffaterre, em 1993. Foi a partir das discussões realizadas durante o encontro da MLA que nasceu a ideia de publicar, em livro, os três relatórios, as intervenções de Pratt e Riffaterre, e mais alguns artigos, os quais traziam posicionamentos pontuais dos diversos comparatistas convidados para debater a questão. O livro daí resultante foi publicado pela John Hopkins University Press, sob o título Comparative Literature in the Age of Multiculturalism, em 1995.

"The Levin Report, 1965: Report on Professional Standards" segue assinado pelos integrantes do comitê, comparatistas de relevo no contexto estadunidense: A. Owen Aldridge, Chandler B. Beall, Haskell Block, Ralph Freedman, Horst Frentz, J. C, La Drière, Alain Renoir e René Wellek. Uma das mais visíveis preocupações do relatório é a definição de parâmetros mínimos para a disciplina, tendo em vista a sua crescente institucionalização dentro das ciências humanas na universidade estadunidense:

Members of the ACLA profess, broadly speaking, a set of common objectives. What is needed with some urgency, before our subject gets too thinly spread, is a set of minimum standards. A preliminary questions arises as to whether it is necessarily desirable or practical that Comparative Literature be represented in every institution; whether it does not make special demands, in the way of linguistic preparation and intellectual perspective, which ought to reserve it for the more highly qualified students [...] at this point we venture to suggest that, where it is not represented in a curriculum, it should not be introduced without a good deal of institutional 
heart-searching of the facilities and requirements elsewhere (LEVIN, 1995, p. 21).

Com a expansão da Literatura Comparada nos Estados Unidos, uma das preocupações mais evidentes no relatório de 1965 era o status da disciplina na academia estadunidense, preocupação já visível no subtítulo do relatório e na insistência de se reservar o espaço de investigação da disciplina aos estudantes mais altamente qualificados. Nesta época, os cursos de literatura comparada strictu sensu eram oferecidos somente nos Graduate Programs, com o status equivalente aos Programas de Pós-Graduação (mestrado e doutorado) brasileiros. Caracterizada como uma disciplina de elite, posto que aos candidatos a estes programas exigia-se o pleno domínio de pelo menos duas (por vezes três) tradições literárias nacionais em línguas distintas, colocava-se um problema institucional: deveria a literatura comparada ocupar um departamento específico nas universidades, ou seria mais apropriado manter seu caráter de disciplina de entremeio, posto que sua eficiência depende do trabalho de base realizado nos dos departamentos de língua e literaturas estrangeiras? De acordo com o relatório de 1965, os Programas de Pós-Graduação em Literatura Comparada "are not designed to compete with those in the other departments of languages and literatures, but rather to augment and bridge them, and that there must consequently be a certain amount of departmental interdependence (LEVIN, 1995, p. 22). Todavia, o relatório ressalta as vantagens administrativas, em especial relacionadas aos planos orçamentários, de se ter um departamento central na universidade: "an autonomous department may bring with it budgetary advantages, while administrative convenience may profit from the pattern of a central professor flanked by a number of cooperative colleagues" (LEVIN, 1995, p. 22).

O relatório de 1965 é também bastante claro no que diz respeito ao valor atribuído ao trabalho com os cursos dedicados às grandes obras canônicas da literatura ocidental, quando trabalhados em tradução no ambiente acadêmico. Ainda que considerando aceitável o trabalho intelectual com traduções de obras provenientes de línguas remotas (e o relatório não é claro quando diz respeito à definição do que entende por "línguas remotas"), ele dedica considerável esforço em delimitar as atividades envolvendo a discussão de obras em tradução. Todavia, o esforço maior é o de delimitar claramente a linha que separa os cursos de "Literatura Geral" da abordagem específica realizada pelo comparatismo, caracterizada, antes de tudo, pelo acesso aos textos em sua língua original de produção e pelo conhecimento da tradição literária nacional na qual tais textos se inserem: "a further distinction might conceivably by drawn between Humanities or World Literature or Great Books at the undergraduate level and Comparative Literature as a graduate discipline (LEVIN, 1995, p. 23). Nesta breve citação, torna-se evidente que a questão não implica somente uma interdição à rasura das fronteiras entre os cursos de literatura geral e de literatura comparada, mas sim uma separação entre o trabalho intelectual "de elite" dos comparatistas (nos cursos de mestrado e doutorado) e o realizado ao longo dos cursos de menor escopo, os Undergraduate Courses (equivalentes às licenciaturas curtas e plenas no Brasil).

"The Greene Report, 1975: A Report on Standards", foi redigido por Thomas Greene e assinado por Haskell Block, Nan Carpenter, Frederic Garber, François Jost, Walter Kaiser, Elizabeth Trahan e Herbert Weisinger. Este relatório ecoa alguns pontos já apresentados no relatório anterior, notadamente o apelo a certo elitismo por parte dos comparatistas: "[Comparative Literature] aimed also at the clarification of the great theoretical issues of literary criticism from a cosmopolitan vantage point" (GREENE, 
1995, p. 28). Importante notar aqui que o termo theoretical issues está sendo utilizado não no sentido estrito de "teoria da literatura", mas com um alcance semântico dilatado, tal como Johnathan Culler assinala (1982). Não se pode ignorar que a década de 70 do século XX foi o período de grande penetração do pós-estruturalismo nas universidades estadunidenses, especialmente nos departamentos de línguas e literaturas. O relatório evidencia o crescimento da importância da "proficiência teórica" para os estudos de Literatura Comparada e, simultaneamente, começa a apontar para alguns rasgos de elitismo denunciados no relatório anterior: “the Levin's report is notable for its balance, its judgment, and its elegance, yet its authors did not hesitate to defend a certain elitism which they perceive to be inherent in the nature of their subject" (GREENE, 1995, p. 29). A postura elitista aqui denunciada refere-se ao fato de que o comparatista deve, de acordo com Levin, evitar o trabalho com as traduções, restringindo seu trabalho àquelas tradições literárias que sejam conhecidas a partir da língua na qual sejam produzidas: "a new vision of global literature is emerging, embracing all the verbal creativity during the history of our planet, a vision which will soon begin to make our comfortable European perspectives parochial" (GREENE, 1995, p. 30). Entretanto, o estudo envolvendo as traduções de obras literárias e o próprio processo tradutório é deixado à margem das preocupações comparatistas, uma vez que a perda semântica é considerada irrecuperável:

Courses in translation are potentially of great value to the student, but if no one in the classroom, including the teacher, is in touch with the original language, then some precious has been lost to the learning experience, and something also of our comparatists integrity (GREENE, 1995, p. 32).

Não se pode perder de vista que esta afirmação foi feita em um momento no qual, nas universidades estadunidenses, houve uma grande expansão dos Undergraduate Major Courses de Literatura Comparada, muitos dos quais não atentavam aos requisitos mínimos da prática comparatista, enquanto os Graduate Courses (mestrados e doutorados) continuavam a manter um rigor por vezes excessivo no que dizia respeito aos conhecimentos prévios dos candidatos. Uma das razões sinalizadas no Greene Report como origem desta lacuna entre Graduate e Undergraduate Courses está no enfraquecimento dos departamentos de línguas estrangeiras nos Estados Unidos ao longo da década de 70: "the erosion, if not the withering, of the strenght of foreign language departments in the wake of abolished requirements" (GREENE, 1995, p. 30). Greene, todavia, mostra-se muito preocupado, não com a falta de rigor dos Undergraduate Courses, mas com o tipo de crise que tal enfraquecimento pudesse estar a sinalizar, uma vez que "by definition, any crisis of undergraduate training would be a crisis of graduate training" (GREENE, 1995, p. 32).

"The Bernheimer Report, 1993: Comparative Literature at the Turn of the Century" é o terceiro relatório, o qual foi dirigido por Charles Bernheimer. Os outros professores do comitê foram Johnathan Arac, Marianne Hirsch, Ann Rosalind Jones, Arnold Kuprat, Dominick LaCapra, Sylvia Molloy, Steve Nichiols e Sara Suleri. Um dos motivos que pode ser considerado para a virada metodológica e epistemológica no cenário comparatista é a inexistência de relatório relativo à década de 80 . De acordo com Charles Bernheimer, o relatório de 1985 foi vetado pelo seu diretor, insatisfeito com o resultado, e jamais chegou a ser submetido à ACLA ou mesmo publicado (BERNHEIMER, 1995, p. IX). Desta maneira, este relatório reflete um percurso não de dez, mas de vinte anos de comparatismo nos Estados Unidos, questão que não pode ser 
deixada de lado, especialmente quando se pensa no contexto político das décadas de 80 e 90 nos Estados Unidos. Marcada por uma onda de conservadorismo cujo índice mais expressivo foi a "Era Reagan", este período foi também um dos mais importantes no que diz respeito à abertura da academia para as reivindicações de grupos minoritários. Tal como na Física, também no mercado das ideias age a lei da ação e reação. Institucionalmente, a década de 80 foi marcada pela institucionalização dos estudos feministas e dos estudos étnicos, e pela emergência dos estudos gays e lésbic@s e da teoria queer, a partir da década de 90 do século XX.

Charles Bernheimer observa, ao avaliar os dois relatórios anteriores, que os estudos comparatistas "tended to reinforce an identification of nation-states as imagined comunities with national languages as their natural basis" (BERNHEIMER, 1995, p. 40). Questionando uma das mais arraigadas premissas da disciplina, a de "ler na língua original", torna-se impossível não se ir de encontro à outra das delicadas questões que estão a ser desmanteladas, atualmente, no edifício teórico da disciplina: a questão do eurocentrismo que marca a construção dos cânones literários ocidentais: "Europe is the home of the canonical originals, the proper object of comparative study; so-called remote cultures are peripherical and thence can be studied in translation" (BERNHEIMER, 1995, p. 40). Como resíduo suplementar da resistência à leitura de traduções, produz-se um profundo desconhecimento das culturas minoritárias, mesmo na Europa, e evidencia-se um cânone europeu basicamente constituído por textos literários provenientes das línguas inglesa, francesa, alemã e espanhola: "the apparent internacionalism of the postwar years sustained a restrictive multiculturalism that has recently been challenged from multiple perspectives" (BERNHEIMER, 1995, p. 41). Mesmo que se considere o legado das línguas clássicas, nomeadamente o latim, o sânscrito e o grego, um corpus comparatista assentado sobre sete línguas não pode ser considerado representativo da diversidade lingüística da Europa. Ao lado desta constatação, Bernheimer aponta ainda o risco do patrulhamento a cercear as investigações inter e transdisciplinares, implícito na defesa da literariedade como traço distintivo dos artefatos culturais estudados pelo comparatismo.

O relatório redigido por Charles Bernheimer, bem como as discussões que se produziram em seu entorno, marcaram o ano de 1993 como o momento da virada multiculturalista nos estudos de literatura comparada. Como em todas as grandes viradas, esta reformulação dos rumos epistemológicos da disciplina resultou em ganhos e em perdas. Dos ganhos, o maior deles foi uma fertilização do campo comparatista, a partir da abertura institucionalizada para os estudos culturais, marcando uma tomada de consciência com relação ao papel político da literatura no campo mais amplo dos debates acadêmicos das ciências humanas. Das perdas, a maior delas foi uma fragilização ainda maior da identidade institucional da literatura comparada como campo de investigação, ao assumir seu interesse por objetos de estudo tradicionalmente restritos a outros campos disciplinares, tais como a antropologia e a sociologia ${ }^{3}$.

\footnotetext{
${ }^{3}$ Avaliar retroativamente este corpus composto por três relatórios oficiais, redigidos sob os auspícios de alguns dos mais proeminentes comparatistas estadunidenses, em seus respectivos contextos de atuação intelectual, permite que se compreenda um pouco do impacto institucional da disciplina nas universidades americanas. Permite, também, que se vislumbrem alguns dos interesses institucionais que se ocultam sob algumas posturas moderadas no debate comparatista contemporâneo, particularmente a recusa a aceitar influxos provenientes de áreas como os estudos culturais, o feminismo e os estudos de gênero. A importância dada aqui a este conjunto de relatórios institucionais não deve ser lida como um ato de subserviência ao colonialismo cultural estadunidense, mas sim como o reconhecimento da envergadura
} 
Susan Bassnet afirma em Comparative Literature: A Critical Introduction (1993), que finalmente é possível reconhecer as especificidades do que chama de um "comparatismo pós-europeu". Entre as principais correntes mencionadas por Bassnet, encontram-se os estudos e estratégias interpretativas produzidos por comparatistas na África, na Índia, na China, no Japão e na Coreia (assim como em vários países da América Latina), cujas reflexões acentuam a importância de se avaliar a dialética da dependência cultural, o peso das heranças da dominação colonialista na produção literária, e o produtivo embate entre matrizes culturais eurocêntricas e autóctones.

A voz dos comparatistas latino-americanos, por sua vez, fez-se ouvir particularmente a partir dos anos 70, com Antonio Candido e Ángel Rama. Candido destaca a importância da presença de três fatores para a consolidação de um sistema literário: um conjunto representativo de autores, de obras literárias em circulação e de um público leitor. A aparente simplicidade deste esquema, apresentado em Formação da literatura brasileira (1981), esvai-se quando ele ilustra, por exemplo, que o caráter de "literatura brasileira" da poesia barroca pode ser questionado, posto que à época não havia um público leitor consolidado no país. Rama, por sua vez, desenvolve a noção de "comarca literária" como possibilidade para que se compreenda a heterogeneidade da cultura latino-americana (Rama, 2004 e 2008). As comarcas literárias dizem respeito a regiões geoculturais do continente latino-americano que possuem uma tradição cultural comum, mas que não necessariamente respeitam limites e fronteiras nacionais. A comarca literária do pampa, por exemplo, abrange a literatura e a cultura produzidas na Argentina, no Uruguai e no sul do Brasil. Seguindo as orientações de Rama, seria possível também pensar em comarcas "intranacionais" como, por exemplo, o caso do nordeste brasileiro, produtor de especificidades culturais importantes se comparado à região sul do Brasil ou a uma tradição vanguardista de cunho urbano que medrou (e ainda medra) na região sudeste, particularmente no eixo Rio-São Paulo.

A partir da leitura de Cuntrapunteo cubano del tabaco y el azúcar, do antropólogo cubano Fernando Ortiz, Rama introduziu no comparatismo latinoamericano uma nova categoria analítica: a de transculturação. Diferentemente da noção de aculturação utilizada por Ortiz, que carrega aspectos semânticos negativos, relativos à dependência cultural, a noção de transculturação implica no transplante de aspectos culturais que são apropriados de maneira crítica e recontextualizados na nova cultura. Como exemplo de transculturação na América Latina, pode-se pensar na apropriação e recontextualização que os escritores do boom latino-americano fizeram com relação ao romance, de maneira a vincular através deste gênero narrativo o imaginário do continente. Exemplos de transculturação podem também ser vistos no imaginário religioso, quando um mito tão caro às culturas ibéricas, como o da Virgem Maria, presta-se a reformulações no Novo Mundo, instaurando imagens como as de Nossa Senhora de Aparecida e da Virgem de Guadalupe, de maneira a "racializar" as imagens sagradas de matriz europeia, sinalizando assim processos de sincretismo e hibridismo cultural. Angel Rama e Antonio Candido estabeleceram um profícuo diálogo, o qual resultou em um projeto para a escritura de uma História da literatura latino-americana. Este projeto, depois de várias reformulações, foi concluído sob a coordenação de Ana Pizarro, resultando na publicação de América Latina: palavra, literatura y cultura, em três alentados volumes publicados em 1993.

O pensamento comparatista latino-americano mostra-se preocupado com a

institucional da ACLA, uma importante associação comparatista que em muito contribuiu para a constituição da Associação Internacional de Literatura Comparada. 
inserção da literatura no contexto mais amplo da cultura pelo menos desde a década de 70 do século XX. As propostas de investigação de Ana Pizarro e Antonio Cornejo Polar, ainda que de maneiras diferenciadas, sugerem uma reflexão sobre os processos de transculturação envolvendo América Latina e Europa, o questionamento dos cânones literários eurocêntricos e os influxos entre a literatura latino-americana strictu sensu e outras formas culturais, tais como a literatura oral, o folclore e as modalidades consideradas "populares" de literatura, como o cordel e a literatura infantil. Tais preocupações permitem uma aproximação entre o comparatismo latino-americano com os estudos culturais.

Com o advento dos estudos culturais, uma série de conceitos-chave para a literatura passa a ser profundamente criticados e problematizados, tais como os de fontes/influências, originalidade/imitação e nacional/estrangeiro. Em cada um destes conjuntos binários de termos, o primeiro é sempre valorizado e considerado hierarquicamente superior ao segundo, instaurando assim um jogo de valorações no interior dos próprios conceitos. Em um estudo comparatista que se dedique às influências de Chateaubriand sobre Alencar, por exemplo, o resultado final é a valorização de Atala como obra "original", e a desvalorização de Iracema por ser uma "imitação". Este exercício fatalmente termina por delinear um lugar hierarquicamente superior para Chateaubriand, em oposição a Alencar, relegado à posição de "imitador". Graças a este reiterado exercício de exclusão, evidencia-se a necessidade de exclusões e silenciamentos na constituição dos cânones literários nacionais.

Segundo Claudio Guillém (2005), as influências fazem parte das condições de possibilidade das obras literárias, uma vez que elas transcendem as influências e instauram suas próprias significações. Para corroborar seu pensamento, Guillém reporta-se às palavras de Paul Valéry, quando este utiliza a metáfora do leão e do carneiro para descrever o funcionamento da poesia: "le lion est fait de mouton assimilé", isto é, o leão é feito de carneiro assimilado (VALÉRY, 1941, p. 19). Ao lançar mão da metáfora digestiva para se referir à questão das fontes e influências, Valéry inverte o sistema de valores, apontando para a assimilação competente como o lugar da criação e da instauração da novidade na poesia. Cabe ainda apontar aqui a possível analogia entre o pensamento de Valéry e a antropofagia celebrada pelos modernistas brasileiros.

A revalorização da influência abre espaço para um novo campo de trabalho comparatista. Ao final dos anos 60, a semioticista búlgara Julia Kristeva chega à Paris e, em um dos seminários coordenados por Roland Barthes, introduz nas discussões de então o pensamento de Mikhail Bakhtin. Ao reformular o pensamento bakhtiniano junto a outros intelectuais que, mais tarde, fundariam a revista Tel Quel, Kristeva apropria-se de noções como "discurso de outrem" (desenvolvida por Bakhtin em Marxismo e filosofia da linguagem) e "dialogismo" (cunhada por Bakhtin a partir de seus estudos em A poética de Dostoiévski) para então formular a sua noção de "intertextualidade". Segundo Kristeva, em Seméiotikè: recherches pour une sémanalyse (1969), "todo texto se constrói como mosaico de citações, todo texto é absorção e transformação de um outro texto. No lugar da noção de intersubjetividade, instala-se a de intertextualidade, e toda linguagem poética é lida, pelo menos, como dupla" (KRISTEVA, 1969, p. 146).

A partir daí, a própria noção de escrita, para Kristeva, será lida como uma modalidade de leitura expropriativa: a escrita é a faceta produtiva da leitura. Esta ideia, aliás, será retomada por Roland Barthes em Le plaisir du texte (1973), quando este diferencia duas modalidades de textos: os textos legíveis e os textos escrevíveis. Para 
Laurent Jenny, por sua vez, a intertextualidade não é uma adição confusa e misteriosa de influências, mas o trabalho de transformação e assimilação de vários textos operado por um texto centralizador que mantém o comando do sentido. Em seu artigo "La stratégie de la forme" (1976, p. 257-281), Jenny redimensiona a noção de intertextualidade no campo dos estudos de literatura comparada. Pensada desta forma, a intertextualidade introduz um novo modo de leitura que solapa a linearidade do discurso literário. Cada referência textual aponta para o lugar de uma dupla alternativa: ou seguir adiante, considerando tal referência como mera coincidência do encadeamento textual ou, então, voltar ao texto de origem, operacionalizando uma espécie de anamnese, ou seja, uma invocação voluntária do passado em que a referência intertextual aparece como elemento discursivo deslocado, originário de um contexto específico que, no momento da citação, é apagado. A intertextualidade configura-se então como uma espécie de citação inconsciente ou automática realizada sem aspas e sem a explicitação do texto de origem.

A Escola de Konstanza e a Rezeptionästetik, tendo como expoentes os nomes de Wolfgang Iser (1996) e Hans Robert Jauss (1994), reinstauram o lugar privilegiado do leitor no processo de significação literária. Reabilitando o lugar do leitor como ponto privilegiado para a produção de significado, a mais importante das interfaces entre dois estudos de recepção e a noção de intertextualidade é a de que a intertextualidade, como fenômeno textual, sempre se dá no momento da recepção. De nada adianta uma referência ou citação em um texto literário se o leitor não é capar de recuperar, a partir de seu histórico de leituras e de seu horizonte de expectativas com relação ao texto que tem em mãos, o papel que uma citação ou uma alusão operam na tessitura de uma obra literária.

\section{DESLOCAMENTOS E INTERFACES: A REINVENÇÃO DO COMPARATISMO NA CONTEMPORANEIDADE}

Os influxos provenientes do feminismo, dos estudos pós-coloniais e da filosofia pós-estruturalista, entre outras correntes do pensamento crítico, têm contribuído para uma reformulação e um alargamento dos campos de atuação, dos objetos de estudo e dos métodos investigativos. Os limites do comparatismo, questão presente na pauta dos debates desde os primeiros momentos do estabelecimento da disciplina, são uma vez mais problematizados, ocupando o centro das discussões. A principal diferença entre as discussões contemporâneas e as polêmicas do passado é a evidência de que vários dos conceitos mais sólidos do comparatismo, tais como os de "identidade cultural", "nação", "língua nacional" e "literariedade" passam a ser questionados, uma vez que são denunciados como construções historicamente marcadas, ou ainda, como ficções conceituais. Consequentemente, abrem-se fissuras teóricas que permitem vislumbrar os comprometimentos de tais categorias como estruturas acumpliciadas com as hegemonias acadêmicas.

Até recentemente, o artefato literário era visto com uma espécie de "fato natural". Contudo, trabalhos contemporâneos vêm questionando o caráter apriorístico do discurso literário, uma vez que, sendo a literatura um discurso resultante de práticas sociais intersubjetivas, sua especificidade não passa de um jogo de convenções cristalizado em determinado momento histórico, implicado por linhas de poder e, 
justamente por isso, passível de câmbios e oscilações ao longo do tempo. A noção de "literatura nacional", por exemplo, vem sendo avaliada atualmente em seus estritos vínculos com os processos de constituição das "comunidades imaginadas" (termo que Benedict Anderson (1991) utilizou para descrever os processos históricos de constituição dos nacionalismos europeus no século XVIII). O valor artístico dos artefatos literários, por grande tempo considerado uma qualidade intrínseca, passa a ser visto como o resultado da interação de fatores extrínsecos, fatores estes que sempre incluem nuances políticas. A partir dos estudos culturais, a teoria da literatura contemporânea "historiciza" a genealogia de suas próprias categorias de análise, e a pretensão ao universalismo é abandonada em nome de uma reflexão sobre as condições históricas e contextuais nas quais seus discursos foram formulados. O projeto de uma "poética geral" e de uma "história da literatura geral" (já questionados, em alguns aspectos, desde os anos 50 por René Wellek) são abandonados e substituídos por uma percepção transdisciplinar, que vê a literatura como uma prática discursiva em permanente diálogo com outros processos de semiose cultural, "contaminada" (no sentido derrideano do termo) por outros campos de saber (SCHMIDT, 2007, p. 11-34).

Com estas primeiras indagações sobre o caráter discursivo e historicamente situado da literatura e dos discursos sobre a literatura, os cânones revelam-se como os maiores esteios de uma tradição euro/falocêntrica e racista, que privilegiou certas vozes em detrimento de outras na construção dos paradigmas de referência e de valoração estética. O texto literário passa a ser avaliado em relação com outras manifestações culturais, sem o privilégio concedido pela "literariedade", e os critérios valorativos/judicativos passam a oscilar a partir do locus de enunciação do comparatista. Isso não implica na falência da crítica literária (posição defendida com ardor no Brasil por alguns críticos mais conservadores), mas sim na tomada de consciência de que os valores que pautam a crítica literária não são absolutos. A literatura comparada, desta forma, renova-se, problematizando os pressupostos paradigmáticos da teoria da literatura e fazendo a crítica forçar-se a uma metacrítica, no sentido de conscientizar-se do seu locus político e enunciativo.

A problematização das visões lineares e teleológicas da História faz-se presente nas discussões sobre periodização e historiografia literárias. A tradição literária passa a ser considerada não como o mero acúmulo da produção de textos ao longo da história, mas como um processo constante de reescritura do passado a partir de problemas do presente, estabelecendo, nos estudos comparatistas, uma verdadeira dialética entre passado e presente. A relativização dos processos de constituição dos cânones nacionais abre um espaço importante para grupos minoritários que dele se viram excluídos ao longo da história. Assumindo suas próprias vozes e reivindicando tradições culturais próprias, estes grupos passam a lutar pela constituição de outros cânones, ou então, pela flexibilização dos parâmetros do cânone com vistas a abrir espaço para outras obras. As críticas feministas passam a dedicar esforços aos trabalhos de "arqueologia literária", recuperando a produção das mulheres deixadas à margem da historiografia literária "oficial" e canônica. Um importante exemplo deste trabalho no contexto brasileiro é dado pelos três volumes da antologia Escritoras brasileiras do século XIX, organizada por Zahidé Lupinacci Muzart (2000; 2004; 2009), nos quais são resgatados dos arquivos esquecidos os nomes de mais de cento e cinquenta escritoras brasileiras deixadas à margem dos manuais de historiografia literária brasileira, manuais estes sintomaticamente escritos por homens.

Discutir e relativizar o cânone viabiliza o abalo de tradições e sistemas de 
valores instituídos pelos centros de poder. A literatura comparada articula, no presente, um importante papel nestas discussões. Enquanto as nações periféricas relativizam os critérios estéticos impostos pelas metrópoles, os países centrais são assolados pelas reivindicações de grupos subalternizados, nos quais mulheres, negros e homossexuais reivindicam parâmetros alternativos para a avaliação da produção cultural em um importante gesto de descolonização do imaginário. Tais discussões não deslocam apenas nossa compreensão acerca de noções como "literatura", "identidade", "nação" e "valor estético", mas contribuem para uma discussão mais ampla sobre o universal e o particular, instaurando novas possibilidades éticas que invocam a alteridade como conceito-chave na crítica cultural. Dito de outro modo, o papel do comparatismo, no cenário atual dos estudos literários e culturais, pode ser sintomaticamente definido como a consolidação simultânea de um campo disciplinar e de um saber/poder sobre a diferença cultural. Redimensionar os regimes de representação das comunidades humanas, preocupação comum à literatura comparada e aos estudos culturais neste início de século, é o primeiro passo para que se construam novas possibilidades de relacionamento no campo social.

É fundamental a reflexão sobre as margens da poética - isto é, sobre os limites e fronteiras da teoria literária e do comparatismo - para compreender a produção contemporânea, perpassada por múltiplas marcas de alteridade. Por que é importante a produção de saberes comparatistas no mundo atual? Qual a relevância destes saberes, e de que maneiras eles se inserem na produção contemporânea do conhecimento? De que formas o estudo das alteridades nas tradições literárias não-europeias contribuem na compreensão dos diálogos transnacionais? Que tipo de discussão pode ser articulada a partir da emergência de paradigmas de análise literária tais como o ecofeminismo e a ecocrítica em um momento histórico no qual a qualidade de vida em escala global, a erradicação das exclusões e a luta pelos direitos humanos encontram-se no centro dos debates intelectuais? Muitos intelectuais contemporâneos têm salientado o fato de que um dos limites mais insuperáveis da razão humanista ocidental diz respeito às maneiras pelas quais a modernidade lidou com as estruturas de alteridade e de diferença. Tal como pergunta Mary Louise Pratt (2004), como eliminar, nos níveis epistemológico e político, as desigualdades sociais? Uma resposta (ainda que breve) para estas questões inclui a problematização dos saberes nas condições históricas contemporâneas, e a consciência de que os processos de significação cultural estão sempre contextualizados e determinados pela conjuntura histórica e ideológica de seu tempo. A tendência metadisciplinar da literatura comparada a caracteriza como um importante espaço intelectual para avançar nestas questões, posto que, desde seu nascimento, este campo de estudos manteve um permanente questionamento tanto de sua definição, do seu objeto e do seu método, quanto da própria necessidade de flexibilização da categoria "disciplina", posto o seu constante diálogo com a história, a teoria e a crítica literárias, bem como com outras áreas do saber.

A articulação da pesquisa em literatura comparada a uma reflexão de cunho "metacrítico" e "metateórico" permite uma ampliação do papel do comparatismo na área das ciências humanas e as suas contribuições fundamentais para a compreensão das alteridades e para o estabelecimento de uma consciência e de uma cidadania planetárias, tomando como ponto de partida a compreensão da cultura do outro. Para Gayatri Spivak, a ideia das coletividades transnacionais que atravessam e/ou trespassam fronteiras, em especial quando sob os auspícios da literatura comparada, deveriam ser pensadas não em termos continentais, mundiais ou globais, mas sim em termos de uma 
planetaridade compartilhada por toda a humanidade. Spivak reinterpreta e reformula a noção de globalização ao contrastá-la com o termo planetaridade, enfatizando assim a alteridade e a humanidade do planeta, em oposição ao caráter de construção e de artificialidade do globo. Esse novo termo (a "planetaridade") permite uma visão renovada dos processos econômicos e culturais do mundo contemporâneo, uma vez que o vocábulo "globalização" se encontra já desgastado. Spivak argumenta que enquanto a noção de "globo" remete para um constructo abstrato e artificial no qual ninguém vive, a ideia de "planeta" pertence a um outro sistema conceitual, no qual se enfatizam as diferente relações que nós, humanos, estabelecemos empiricamente com o lugar concreto em que habitamos:

The globe is on our computers. No one lives there. It allows us to think that we can aim to control it. The planet is in the species of alterity, belonging to another system; and yet we inhabit it, on loan. It is not really amenable to a neat contrast with the globe. I cannot say "the planet, on the other hand." When I invoke the planet, I think of the effort required to figure the (im)possibility of this underived intuition (SPIVAK, 2003, p. 72).

O impacto dos estudos culturais britânicos, na tradição de nomes como Raymond Williams e Stuart Hall, ao revalorizar manifestações as culturais das classes subalternizadas, e dando atenção para a cultura popular, impacta de maneira intensa os estudos literários, e uma das principais consequências é o questionamento das categorias de análise mais basilares para a história da literatura comparada, tais como as de nação, língua nacional e literariedade (esta última, uma espécie de "porto seguro" teórico para os estudos literários em cena desde o advento do formalismo russo). $\mathrm{Na}$ América Latina, merece destaque o questinamento feito à noção de literaridade por Antonio Cornejo Polar com a sua defesa da heterogeneidade (simultaneidade do oral e do escrito) como traço distintivo das literaturas andinas.

Um dos traços diferenciadores do pensamento de Cornejo Polar é a sua insistência no fato de que o ponto de partida para o historiador das literaturas latinoamericanas é a sua interpretação pessoal daquilo que conta como "literatura" em sua interpretação e avaliação da herança literária. Para ele, a literatura não é apenas um reflexo ou produto da sociedade na qual foi engendrada, mas uma força produtiva que contribui para o delineamento do perfil cultural desta mesma sociedade. Em outras palavras, a literatura não é apenas uma manifestação cultural de caráter derivativo, mas é também produtiva. Outro traço importante de seu pensamento é a insistência na diferença irredutível que existe entre a temporalidade da tradição popular e a da tradição letrada das elites latino-americanas, fortemente marcadas pela herança do pensamento iluminista que guiou o processo de formação das nações latino-americanas. Isto é de grande monta para que se compreenda a questão da marginalização das literaturas dos povos originários da América Latina (sejam as tradições orais, independentemente da língua que utilizam, sejam as manifestações literárias escritas em línguas autóctones, tais como o aimará e o quéchua). Para ele, a tradição latino-americana forma uma totalidade marcada por uma natureza contraditória entre seus diferentes setores e subsistemas, dos quais o confronto mais visível é o embate entre as tradições orais autóctones e a tradição escrita trazida pelos europeus:

De fato, como literaturas produzidas por classe e etnias dominadas, [as literaturas latino-americanas de expressão autóctone] estão atomizadas e nãocomunicantes: formam, na realidade, verdadeiros arquipélagos, e não está 
claro se constituem sistemas independentes ou se, em alguns casos, são subsistemas que convergem para um determinado eixo unificador (CORNEJO POLAR, 2000, p. 29).

A importância de se recontextualizar o potencial semiótico da literatura ao produzir sentidos em diferentes contextos históricos coloca o comparatista, já de antemão, em uma postura de leitura dupla, levando em conta simultaneamente o contexto de produção e o de recepção de uma obra: "a História Literária passa a ser a história da produção e recepção de textos, e, para o historiador, esses textos constituem ao mesmo tempo documentos do passado e experiências do presente" (COUTINHO, 2003, p. 77). Cornejo Polar, em outros termos, coloca a mesma questão, ao afirmar que "reconhecer um passado como nosso próprio passado supõe um certo modo de definir o presente e de identificar a índole do futuro" (CORNEJO POLAR, 2000, p. 52). Tomar a chegada dos espanhóis, por um lado, ou a tradição pré-colombiana, por outro, como ponto de origem das tradições literárias da América Latina denuncia dois posicionamentos bastante distintos com relação à valoração da tradição herdada e ao que se projeta como possibilidade para o futuro.

Partindo do caminho já aberto pelo comparatista palestino Edward W. Said em Orientalism (1978), Cornejo Polar salienta que a Europa, ao mesmo tempo em que "inventa" a América, "inventa-se" também a si mesma (e até com maior eficácia do que "inventa" a América). Imaginar o outro é um gesto interpretativo bastante produtivo na tarefa de figurar a si mesmo. Não se deve, em nenhum momento, subestimar o poder da imagem sobre aquilo que é imaginado:

[...] cada sujeito decide a história que lhe corresponde, à qual pertence e à qual se deve. [...] muitos hispanistas imaginam que as nações andinas começaram com a conquista, e todos os indigenistas encontram as raízes nacionais muito antes, na época pré-hispânica (CORNEJO POLAR, 2000, p. 57).

A importância estratégica da literatura comparada para o desenvolvimento das ciências humanas articula-se no nível de reconhecimento internacional que o comparatismo vem obtendo no contexto mais amplo das ciências sociais e humanidades. Em tempos de globalização e de multiculturalismo, o Ensino Superior vem sendo mercantilizado, enquanto a diferença cultural é reduzida à forma de commodities no mercado das ideias, com vistas a integrar a economia global como valor de escambo a serviço do capital. Resgatar o compromisso da crítica cultural com o embate de ideias e com a problematização da cultura própria e da cultura alheia (CARVALHAL, 2003) é uma questão estratégica neste sombrio iniciar de século, o qual ameaça as culturas minoritárias e/ou subalternizadas com a instrumentalização do ensino de línguas estrangeiras. É esquecido o fato de que, agregada à língua do outro, está uma cultura e um sistema conceitual que não pode ser negligenciado a partir de uma compreensão rasa dos processos de tradução cultural. Sob o mito da transparência dos processos de tradução cultural, esconde-se uma lógica perversa que obnubila as diferenças. Se, tal como afirma Susan Bassnet (1998), todo processo de tradução cultural implica em uma perda e em um ganho, cumpre restituir a importância de se potencializar os ganhos e minimizar as perdas através do reconhecimento das alteridades. 


\section{BIBLIOGRAFIA}

AHMAD, Aijaz. "Show Me The Zulu Proust": Some Thoughts On World Literature. Revista Brasileira de Literatura Comparada. ABRALIC/Curitiba (UFPR), n. 17, 2010, p. 11-46.

ANDERSON, Benedict. Imagined Communities: Reflections On The Origin and Spread of Nationalism. London: Verso, 1991.

BAKHTIN, Mikhail. Marxismo e filosofia da linguagem. São Paulo: HUCITEC, 2004.

A poética de Dostoiévski. Trad. Paulo Bezerra. Rio de Janeiro: Forense Universitária, 2008.

BARTHES, Roland. Le plaisir du texte. Paris: Seuil, 1973.

BASSNET, Susan. Comparative Literature: A Critical Introduction. Oxford: Blackwell, 1993.

Translation Studies. $4^{\text {th }}$ Revised Edition. London: Routledge, 1998.

BERNHEIMER, Charles (Ed.). Comparative Literature In The Age Of Globalization. Baltimore: The John Hopkins University Press, 1995.

The Bernheimer Report, 1993: Comparative Literature At The Turn Of The Century. In: ___ (Ed.). Comparative Literature In The Age Of Globalization. Baltimore: The John Hopkins University Press, 1995. p. 39-50.

CANDIDO, Antonio. Formação da literatura brasileira: momentos decisivos. Belo Horizonte: Itatiaia, 1981 (2 volumes).

CARVALHAL, Tania Franco. O próprio e o alheio: ensaios de literatura comparada. São Leopoldo: UNISINOS, 2003.

e COUTINHO, Eduardo (organização). Literatura comparada: textos fundadores. Rio de Janeiro: Rocco, 1994.

CASANOVA, Pascale. The World Republic Of Letters. Translated by M. B. de Bevoise. Cambridge: Harvard University Press, 2004.

. Literature As A World. New Left Review. Number 31, Jan./Feb. 2005, p. 71-90.

CORNEJO POLAR, Antonio. O condor voa. Organização de Mário J. Valdés. Belo Horizonte: UFMG, 2000.

COUTINHO, Eduardo. Introdução. In: . (Organização). Fronteiras imaginadas: cultura nacional/teoria internacional. Rio de Janeiro: Aeroplano, 2001. p. 7-12. 2003.

Literatura comparada na América Latina: ensaios. Rio de Janeiro: EdUERJ,

CROCCE, Benedetto. La letteratura comparata. In: . Problemi di estética. Bari, Gius: Laterza Figli, 1949. p. 71-76.

CULLER, Jonathan. On Deconstruction: Theory And Criticism After Structuralism. Ithaca: Cornell University Press, 1982.

ETIEMBLE, René. Comparaison n'est pas raison. Paris: Gallimard, 1963.

GREENE, Tom et alli. The Greene Report, 1975: A Report On Standards. In: BERNHEIMER, Charles (Ed.). Comparative Literature In The Age of Globalization. Baltimore: The John Hopkins University Press, 1995. p. 28-38.

GUILLÉM, Claudio. Entre lo uno y lo diverso: introducción a la literatura comparada (ayer y hoy). Barcelona: Tusquets, 2005.

ISER, Wolfgang. O ato de leitura: uma teoria do efeito estético. São Paulo: 34, 1996.

JAUSS, Hans Robert. A história da literatura comparada como provocação à teoria da 
literatura. São Paulo: Ática, 1994.

JENNY, Laurent. La stratégie de la forme. Revue Poétique (27). p. 257-281. Paris: Seuil, 1976.

KRISTEVA, Julia. Seméiotikè: recherches pour une sémanalyse. Paris: Éditions du Seuil, 1969.

LEVIN, Harry et alli. The Levin Report, 1965: Report on Professional Standards. In: BERNHEIMER, Charles (Ed.). Comparative Literature In The Age Of Globalization. Baltimore: The John Hopkins University Press, 1995. p. 21-27.

MARINO, Adrian. Comparatisme et théorie de la littérature. Paris: Presses Universitaires de France, 1988.

MORETTI, Franco. Conjectures On World Literature. New Left Review. Num. 1, Jan./Feb. 2000. p. 54-68.

More Conjectures On World Literature. New Left Review. Num. 20, Mar./Apr., 2003. p. 73-81.

MUZART, Zahide Lupinacci (organização). Escritoras brasileiras do século XIX: volume I. 2 ed. Florianópolis; Santa Cruz do Sul: Mulheres; EDUNISC, 2000.

. (Organização). Escritoras brasileiras do século XIX: volume II. Florianópolis; Santa Cruz do Sul: Mulheres; EDUNISC, 2004.

. (Organização). Escritoras brasileiras do século XIX: volume III. Florianópolis;

Santa Cruz do Sul: Mulheres; EDUNISC, 2009.

ORTIZ, Fernando. Cuntrapunteo cubano del tabaco y el azúcar. Caracas: Biblioteca Ayacucho, 1987.

PICHOIS, C. et ROUSSEAU, A. M. La literature comparée. Paris: Armand Colin, 1971.

PIZARRO, Ana (organização). América Latina: palavra, literatura e cultura. Campinas: UNICAMP, 1993. (Três volumes).

PRATT, Mary Louise. Los imaginarios planetarios. Conferência apresentada por ocasião do IX Congresso Internacional da ABRALIC, ocorrido em Porto Alegre, na Universidade Federal do Rio Grande do Sul, em 2004.

RAMA, Ángel. La ciudad letrada. Santiago: Tajamar, 2004.

. Transculturación narrativa en América Latina. México: Siglo Veintiuno, 2004.

. La novela en América Latina: panoramas 1920-1980. Santiago: Universidad

Alberto Hurtado, 2008.

REMAK, Henry H. H. The Future Of Comparative Literature. In: Proceedings Of The Eighth Congress Of The ICLA. Stuttgart: Kunst und Wissen/Erich Bieber, 1980. p. 429437.

SCHMIDT, Rita T. Alteridade planetária: a reinvenção da literatura comparada. Revista Brasileira de Literatura Comparada. Porto Alegre, no 7, p. 113-130, 2005.

A literatura comparada nesse admirável mundo novo. Revista Brasileira de

Literatura Comparada. São Paulo, nº 11, p. 11-34, 2007.

SPIVAK, Gayatri. Death Of A Discipline. New York: Columbia University Press, 2003.

STAËL, Mme. de. De l'Allemagne. Paris: Charpentier, 1844.

TIEGHEN, Paul V. La literature comparée. Paris: Armand Colin, 1951.

TYNIANOV, Iuri. De l'évolution littéraire. In: TODOROV, Tzvetan (édition). Théorie de la littérature: textes des formalistes russes. 2ème édition. Paris: Seuil, 2001. p. 122139.

VALÉRY, Paul. Tel quel I. Paris: Gallimard, 1941. p. 19.

WELLEK, René. A crise da literatura comparada. In: CARVALHAL, Tania e 
COUTINHO, Eduardo (organização). Literatura comparada: textos fundadores. Rio de Janeiro: Rocco, 1994. p. 108-119.

ZHIRMUNSKY, Victor. Sobre o estudo da literatura comparada. Trad. Ruth Nogueira. In: COUTINHO, Eduardo e CARVALHAL, Tania Franco (organização). Literatura comparada: textos fundadores. Rio de Janeiro: Rocco, 1994. p. 199-214. 